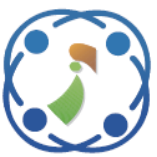

\title{
New Enhanced Symbiotic Organisms Search for Optimal Location and Sizing of Distributed Generation in Radial Distribution System
}

\author{
Umar Umar $^{1,2 *} \quad$ Gema Setyawan $^{1} \quad$ Faanzir Faanzir $^{1,2} \quad$ Firdaus Firdaus $^{1}$ \\ Dimas Fajar U.P ${ }^{1} \quad$ Adi Soeprijanto $^{1} \quad$ Ontoseno Penangsang ${ }^{1}$ \\ ${ }^{1}$ Department of Electrical Engineering, Institut Teknologi Sepuluh Nopember, Surabaya 60111, Indonesia \\ ${ }^{2}$ Department of Electrical Engineering, Universitas Khairun, Ternate 79362, Indonesia \\ * Corresponding author's Email: umarmadjid94@gmail.com
}

\begin{abstract}
Large distributed generation (DG) penetration into the power system needs to be accompanied by proper planning to maximize the benefits and minimize the negative effects that may arise on the system. Determining the location and size of DGs in power systems is a complex issue because it involves hundreds or even thousands of buses and lines distribution. Various studies have been conducted to overcome these problems, including by developing existing methods or even discovering new methods. This study deals with location optimization and sizing DG in the radial distribution system to minimize power loss and voltage deviation. The location of the DG is identified using a loss reduction sensitivity factor (LRSF) while the size of the DG is determined using the improved method of symbiotic organisms search (SOS) called New Enhanced SOS (NeSOS). There are two methods developed in the NeSOS, namely random weighted inverse vector (RWIV) and dual-phase parasitism (DPP). DPP consists of classic parasitism (CP) and random weight parasitism (RWP). The NeSOS is programmed under MATLAB software and validated using 26 mathematical benchmark functions. NeSOS also tested on IEEE 33 and IEEE 69 bus test system and compared with other methods. The simulation results show that the convergence rate of NeSOS is $30 \%$ faster than SOS. NeSOS also provides an average power loss of $1.53 \%$ lower than other methods.
\end{abstract}

Keywords: Benchmark function, Classic parasitism, Dual-phase parasitism, Random weight parasitism, Random weighted inverse vector.

\section{Introduction}

A large DG penetration into the power system provides various technical, economic, and environmental benefits. On the other hand, nonoptimal DG can lead to various new problems such as difficulty in voltage control, reactive power flow management, reduced protection sensitivity, negative effects on power quality, or even reliability and stability problems [1]. The challenge of finding the proper DG location and size has long been the center of attention of researchers and engineers.

An analytical method based on power stability and voltage sensitivity index is proposed in [2]. Optimal size and DG location based on the voltage stability index and continuation power flow are presented in [3]. Zero bus load flow and current injection approaches are proposed in [4]. The analytical formula based iteration method is presented in [5]. Although analytical methods easily handle differentiable functions, they are not capable of solving complex problems that contain nondifferentiable functions which are representing realtimes problems $[6,7]$.

The drawbacks of analytical methods accelerate the development of heuristic methods. Various heuristics methods have been developed to address this problem, such as genetic algorithms (GA) [8], particle swarm optimization (PSO) [9], artificial bee colony (ABC) [10], etc. Those well-recognized algorithms have been successful in solving complex optimization problems.

No free lunch theory (NFL) [11] shows that there is no heuristic method that can solve all optimization problems effectively. The NFL theory 
opens opportunities for researchers to improve existing algorithms to solve different problems or propose new algorithms that are more competitive than existing algorithms. In the past few years, several heuristic methods were introduced including the Flower pollination algorithm (FPA) [12]; Firefly algorithm (FA) [13]; Grey wolf optimizer (GWO) [14]; Ant lion optimizer (ALO) [15]; Crow search algorithm (CSA) [16]; In addition, improved and modified versions of these methods have also been developed.

SOS was first developed by Cheng and Prayogo for complex numerical optimization [17]. Various studies show that SOS has the robustness and good convergent speed [18, 19]. Despite its many advantages, this algorithm still has shortcomings such as lack of organisms variability [20,21], over exploration [22-24], inefficient in computational time $[22,23,25]$, and imbalance between exploration and exploitation $[7,23,24]$. To overcome this problem, various improvements have been performed to the original SOS. Selection and assignment strategies are proposed in [21] to overcome the low diversification of organisms. Panda and Pani [22] proposed orthogonal parallel SOS with an augmented Lagrange multiplier. An orthogonal array is used to increase exploration capability, while parallelism is used to reduce the computational time of the algorithm. Augmented Lagrange multiplier guarantees an optimal solution is achieved. The adaptive benefit factor and the modified parasitic vector are proposed in [23] to set the balance between exploration and exploitation. A Quasi-oppositional based learning and chaotic local search are introduced by Truong [7] to improve the balance between exploration and exploitation of original SOS. A similar method is proposed by Celik [24]. To improve exploration capability, a new parasitism strategy is also utilized in the algorithm. The parasitic vector consists of two random organisms with a probability of 0.5 . Elitism, random coefficients, and modified benefit factors are introduced in [25]. Elitism and random coefficient are applied to the commensalism phase. Elitism is utilized to filter the best organisms for the next generation, while the random coefficient is used to improve the convergence speed of the algorithm. The random coefficient is limited to a range of 0.4 0.9. The parasitism phase is also eliminated to simplify and to reduce the computational time.

In this paper, a new enhanced SOS (NeSOS) is proposed for optimal placement and sizing of DG in the radial distribution system (RDS). Many studies have shown that the most crucial problems with the original SOS are poor in the exploration rates [22-
24]. Inspired by the parasitism strategy proposed in $[23,24]$, this study proposes dual-phase parasitism (DPP) to increase the exploration capabilities in the parasitism phase. DPP consists of classic parasitism (CP) and random weight parasitism (RWP). Another original SOS problem is inefficient in computational time $[7,23,24]$. To overcome this problem, the search space in the phase of mutualism and commensalism is limited, as indicated in [25] by using a random weighted inverse vector (RWIV). The main contributions of this research are: 1 . Using RWIV and DPP to improve SOS performance; 2. Comparing NeSOS with several methods using 26 benchmark functions. 3. Using NeSOS for two real engineering problems.

The rest of this paper is organized as follows: The SOS and NeSOS algorithms are explained in section 2. Section 3 presents NeSOS validation using 26 benchmark functions and two real engineering problems. Finally, section 4 proposes the research conclusions and future work.

\section{Methodology}

\subsection{Overview of the SOS algorithm}

SOS is an algorithm that mimics the symbiotic relationship of living things in an ecosystem [17]. The most popular symbiotic relationships are mutualism, commensalism, and parasitism. The mutualism phase describes the relationship between two organisms $\left(X_{i}\right.$ and $\left.X_{j}\right)$ in the ecosystem, which are mutually beneficial. The relationship between organisms in the phase of mutualism can be formulated as follows:

$$
\begin{aligned}
& X_{i_{-} \text {new }}=X_{i}+\operatorname{rand}(0,1) x\left(X_{\text {best }}-\mu \times b f_{1}\right) \\
& X_{j_{-} \text {new }}=X_{j}+\operatorname{rand}(0,1) x\left(X_{\text {best }}-\mu \times b f_{2}\right)
\end{aligned}
$$

$i$ and $j$ are integers $1,2,3, \ldots$, where $i \neq j . X_{\text {best }}$ is the organism with the best fitness in the ecosystem. $\mu$ is a mutual vector, which is defined as:

$$
\mu=\left(X_{i}+X_{j}\right) / 2
$$

$b f_{1}$ and $b f_{2}$ are benefit factors that can be calculated using:

$$
\begin{aligned}
& b f_{1}=1+\operatorname{round}[\operatorname{rand}(0,1)] \\
& b f_{2}=1+\operatorname{round}[\operatorname{rand}(0,1)]
\end{aligned}
$$




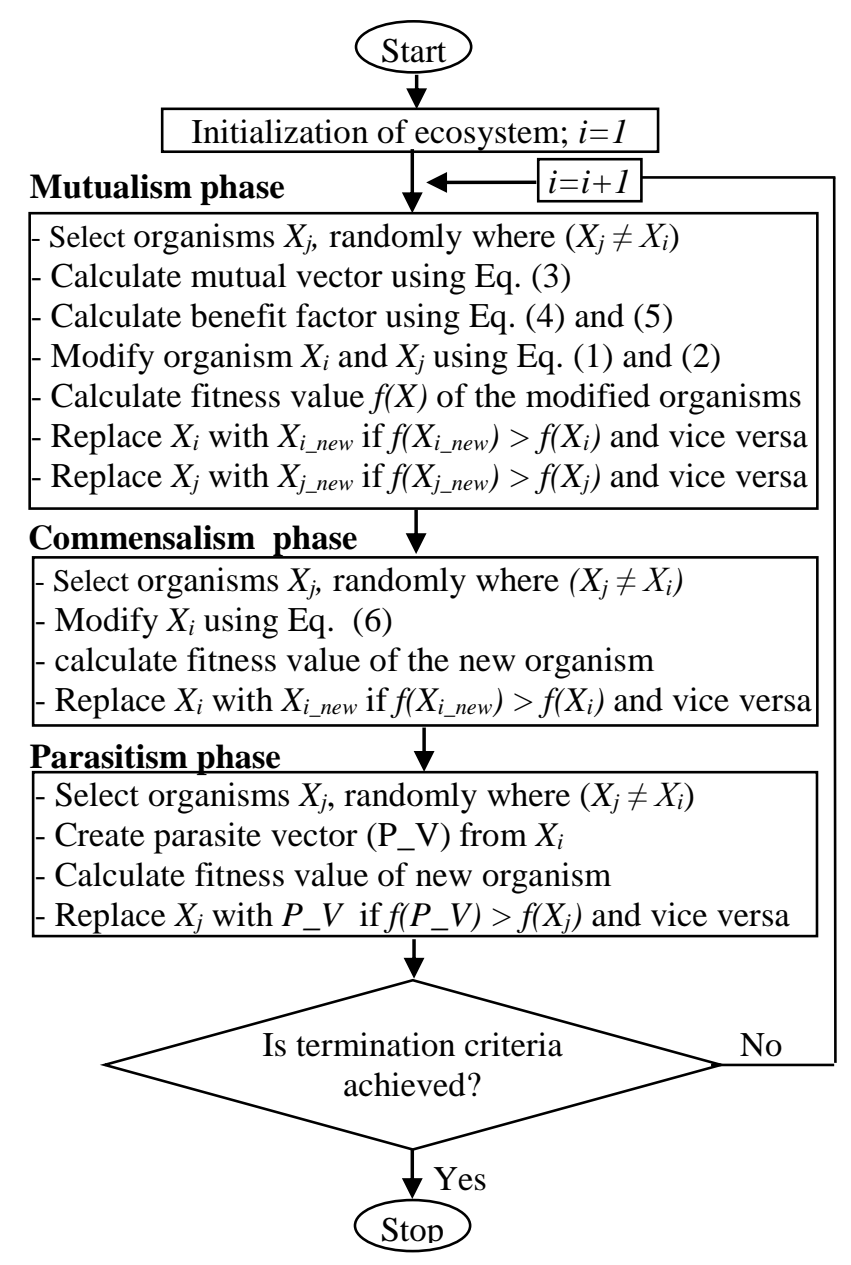

Figure.1 SOS algorithm

In the commensalism phase, the $X_{i}$ organism tries to benefit from $X_{j}$. The new organism results from the interaction between $X_{i}$ and $X_{j}$ as shown in Eq. (6).

$$
X_{i \_n e w}=X_{i}+\operatorname{rand}(-1,1) x\left(X_{b e s t}-X_{j}\right)
$$

The parasitism phase describes the relationship of two organisms, where one gets the advantage, while the other gets a loss. Parasitic vector $\left(\mathrm{P}_{-} \mathrm{V}\right)$ is formed from the cloning of $X_{i}$ organisms that function as parasites. $X_{j}$ is randomly selected to function as hosts of parasitic vectors. If parasitic vector fitness is higher than $X_{j}$, then $X_{j}$ will be replaced by parasitic vector and vice versa. Fig. 1 shows the detail of the SOS algorithm.

\subsection{New enhanced SOS (NeSOS)}

NeSOS in this study is a development version of the original SOS. Modifications are performed in the phase of mutualism, commensalism, and parasitism. In the phase of mutualism and commensalism, modifications are performed to increase the SOS search ability by adopting random weighted differential vector (RWDV) [26] which has been used successfully to improve the performance of the teaching-learning-based optimization algorithm (TLBO). RWDV is defined as follows:

$$
R W D V=0.5 \times[1+\operatorname{rand}(1, D)]
$$

This paper proposes an RWDV modification called random weighted inverse vector (RWIV):

$$
R W I V=1-0.5 \times[1-\operatorname{rand}(1, D)]
$$

RWIV is a random number $(0.5: 1)$. $\mathrm{D}$ is a dimension. Using Eq. (8), then Eq. (1) and (2) in the phase of mutualism are formulated as follows:

$$
\begin{aligned}
& X_{i_{-} \text {new }}=X_{i}+R W I V x\left(X_{\text {best }}-\mu x b f_{1}\right) \\
& X_{j_{-} \text {new }}=X_{j}+R W I V x\left(X_{\text {best }}-\mu x \quad b f_{2}\right)
\end{aligned}
$$

Adopting RWIV in Eq. (8), then Eq. (6) in the phase of commensalism is formulated as follows:

$$
X_{i \_n e w}=X_{i}+R W I V x\left(X_{b e s t}-X_{j}\right)
$$

Modifications in the parasitism phase were carried out to narrow the search space by adopting random weight (RW) from the crow search algorithm (CSA) [16]. Askarzadeh uses RW to determine individual distances in $m$ and $m+l$ iterations. The RW is formulated as follows:

$$
R W=\operatorname{rand}(01) \times \operatorname{rand}(a, b)
$$

$a$ and $b$ in Eq. (12) are specified by the user. In this paper, $a=-2$ and $b=2$. Using Eq. (12), the new position of the organism in the parasitism phase can be written as follows:

$$
X_{i_{-} \text {new }}=X_{i}+R W x\left(X_{\text {best }}-X_{i}\right)
$$

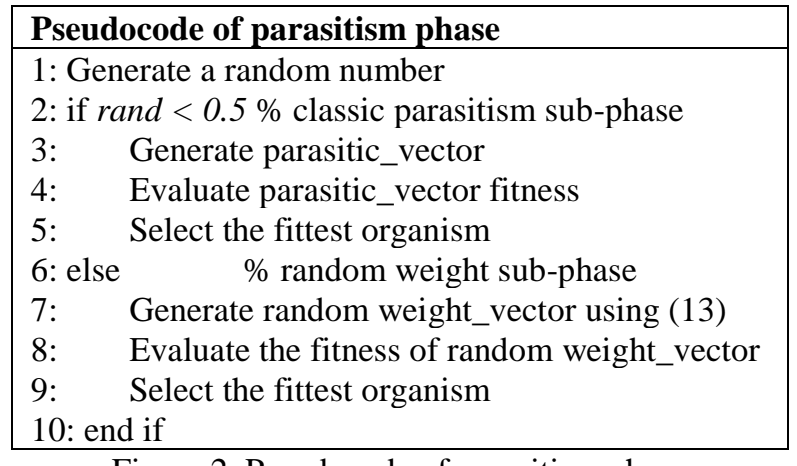

Figure 2. Pseudocode of parasitism phase 
To increase individual variability, the parasitism phase is divided into two sub-phases (dual phase parasitism), namely RWP and CP. RWP is a parasitism phase that uses Eq. (13) as a parasitic vector, while $\mathrm{CP}$ follows the parasitism phase of the original SOS. Modifications to the parasitism phase are explained in Fig. 2.

\section{NeSOS validation}

NeSOS validation is performed in two stages. In the first stage, NeSOS performance is tested using 26 complex mathematical functions. The second stage using real problems in the field of electrical engineering. In this section, NeSOS is used to optimize DG location and size by using the IEEE 33 and IEEE 69 bus testing systems.

\subsection{Benchmark function}

The performance of the proposed algorithm is tested using 26 benchmark functions as shown in Table 1[17]. Functions 1 through 11 are 2 dimensions, whereas functions 12 and 13 are 4 and 5-dimensional functions respectively. Functions 14 and 15 are 10-dimensional functions, and the rest are 30-dimensional functions.

\subsubsection{The effect of RWIV and DPP}

To determine the effect of RWIV and DPP in the algorithm, a performance test is conducted on SOS, RWIV, and DPP using the Ackley function. Ackley has a dimension of 30 and a minimum value of 0 [17]. The SOS parameters used are: Ecosystem number $(n)=50$; Maximum of iteration $=3000$; Error $=1 \times 10^{-12}$. The algorithm is run 20 times for each scheme. The algorithm stops if the error is smaller than $1 \times 10^{-12}$ or the iteration equals the maximum iteration. The best fitness, mean, standard deviation (SD), and iterations average (Iter avg) are

Table 1. Benchmark function

\begin{tabular}{|c|c|c|c|}
\hline No & Function & No & Function \\
\hline 1 & Beale & 14 & Zakharov \\
\hline 2 & Easom & 15 & Michalewicz10 \\
\hline 3 & Matyas & 16 & Step \\
\hline 4 & Boha chevsky1 & 17 & Sphere \\
\hline 5 & Booth & 18 & Sum squares \\
\hline 6 & Michalewicz2 & 19 & Quartic \\
\hline 7 & Schaffer & 20 & Schwefel 2.22 \\
\hline 8 & Six Hump Camel Back & 21 & Schwefel 1.2 \\
\hline 9 & Bohachevsky2 & 22 & Rosenbrok \\
\hline 10 & Bohachevsky3 & 23 & Dixon-Price \\
\hline 11 & Schubert & 24 & Rastrigin \\
\hline 12 & Colville & 25 & Griewank \\
\hline 13 & Michalewicz5 & 26 & Ackley \\
\hline
\end{tabular}

Table 2. The effect of RWIV and DPP in the algorithms

\begin{tabular}{|c|c|c|c|}
\hline Description & Original SOS & RWIV & DPP \\
\hline Best Fitnes & $6.8301 \mathrm{E}-13$ & $2.564 \mathrm{E}-14$ & $3.7748 \mathrm{E}-13$ \\
\hline Mean & $1.13669 \mathrm{E}-12$ & $7.16399 \mathrm{E}-13$ & $7.68275 \mathrm{E}-13$ \\
\hline SD & $4.18995 \mathrm{E}-13$ & $2.31214 \mathrm{E}-13$ & $1.94675 \mathrm{E}-13$ \\
\hline Iter avg & 98.75 & 60.95 & 58.55 \\
\hline
\end{tabular}

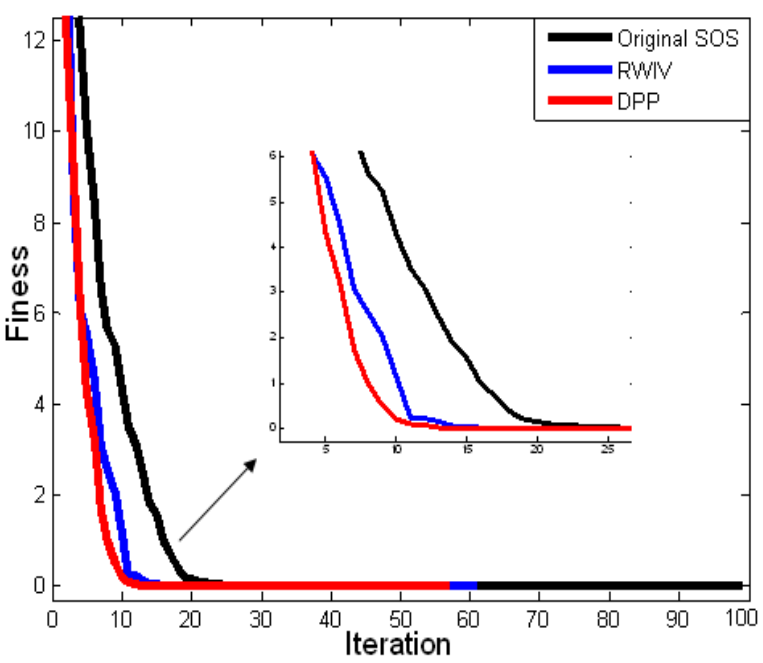

Figure.3 Convergence curve of SOS, RWIV and DPP

reported in Table 2. The convergence curve of SOS, RWIV and DPP are shown in Fig. 3.

The mutualism and commensalism phases play an important role in the process of exploitation of organisms to reach the expected convergence point. Random numbers in Eq. (1), (2) and (6) are very important in controlling the speed of algorithm convergence, but they have a wide search range so that the search space becomes large. As a result, the convergence speed becomes low. Table 2 and Fig. 3 show that narrowing the search space in the range of 0.5 to 1 using RWIV causes the convergence curve to decrease drastically, the iteration becomes smaller thereby saving computing time. In addition, the best fitness, mean and SD are better than original SOS.

The DPP Strategy in parasitism phase allows the algorithm to explore different regions of the search space while avoiding population concentration in high fitness areas, by offering around $50 \%$ of new organisms from RWP. As seen in Table 2 and Fig. 3, the DPP strategy causes the convergence curve to decrease dramatically and the number of iterations to reach the global optimum is lower. The best fitness, average and SD are better than original SOS which uses classical parasitism.

\subsubsection{Validation using 26 benchmark functions}

To validate the performance of the proposed algorithm, the optimization results use 26 
Table 3. Comparison of NeSOS and other algorithms

\begin{tabular}{|c|c|c|c|c|c|c|c|c|c|}
\hline No & Function & Min & \begin{tabular}{|l|} 
Description \\
\end{tabular} & GA[17] & PSO[17] & BA[17] & DE[17] & SOS & NeSOS \\
\hline \multirow[t]{3}{*}{1} & \multirow[t]{3}{*}{ Beale } & \multirow[t]{3}{*}{0} & Mean & 0 & $\mathbf{0}$ & $1.88 \mathrm{E}-5$ & $\mathbf{0}$ & $\mathbf{0}$ & $\mathbf{0}$ \\
\hline & & & $\mathrm{SD}$ & 0 & 0 & $1.94 \mathrm{E}-5$ & 0 & 0 & 0 \\
\hline & & & Iter avg & NA & NA & NA & NA & 52.92 & 15.88 \\
\hline \multirow[t]{3}{*}{2} & \multirow[t]{3}{*}{ Easom } & \multirow[t]{3}{*}{-1} & Mean & -1 & -1 & -0.99994 & -1 & -1 & -1 \\
\hline & & & SD & 0 & 0 & $4.5 \mathrm{E}-5$ & 0 & 0 & 0 \\
\hline & & & Iter avg & NA & NA & NA & NA & 56.24 & 19.2 \\
\hline \multirow[t]{3}{*}{3} & \multirow[t]{3}{*}{ Matyas } & \multirow[t]{3}{*}{0} & Mean & $\mathbf{0}$ & $\mathbf{0}$ & $\mathbf{0}$ & $\mathbf{0}$ & $\mathbf{0}$ & $\mathbf{0}$ \\
\hline & & & $\mathrm{SD}$ & 0 & 0 & 0 & 0 & 0 & 0 \\
\hline & & & Iter avg & NA & NA & NA & NA & 23.64 & 9.8 \\
\hline \multirow[t]{3}{*}{4} & \multirow{3}{*}{$\begin{array}{c}\text { Boha- } \\
\text { chevsky1 }\end{array}$} & \multirow[t]{3}{*}{0} & Mean & $\mathbf{0}$ & $\mathbf{0}$ & 0 & $\mathbf{0}$ & $\mathbf{0}$ & 0 \\
\hline & & & SD & 0 & 0 & 0 & 0 & 0 & 0 \\
\hline & & & Iter avg & NA & $\mathrm{NA}$ & NA & NA & 24.88 & 12.68 \\
\hline \multirow[t]{3}{*}{5} & \multirow[t]{3}{*}{ Booth } & \multirow[t]{3}{*}{0} & Mean & $\mathbf{0}$ & $\mathbf{0}$ & 0.00053 & $\mathbf{0}$ & $\mathbf{0}$ & $\mathbf{0}$ \\
\hline & & & $\mathrm{SD}$ & 0 & 0 & 0.00074 & 0 & 0 & 0 \\
\hline & & & Iter avg & NA & NA & NA & NA & 88.28 & 88.44 \\
\hline 6 & Micha- & -1.8013 & Mean & -1.8013 & -1.57287 & -1.8013 & -1.8013 & -1.8013 & -1.8013 \\
\hline & lewicz2 & & SD & 0 & 0.11986 & 0 & 0 & 0 & 0 \\
\hline & & & Iter avg & NA & NA & NA & NA & 14.96 & 6.84 \\
\hline 7 & Schaffer & 0 & Mean & 0.00424 & $\mathbf{0}$ & 0 & $\mathbf{0}$ & $\mathbf{0}$ & $\mathbf{0}$ \\
\hline & & & SD & 0.00476 & 0 & 0 & 0 & 0 & 0 \\
\hline & & & Iter avg & NA & NA & NA & NA & 99.92 & 16.84 \\
\hline 8 & Six Hump & -1.03163 & Mean & -1.03163 & -1.03163 & -1.03163 & -1.03163 & -1.03163 & -1.03163 \\
\hline & Camel & & $\mathrm{SD}$ & 0 & 0 & 0 & 0 & 0 & 0 \\
\hline & Back & & Iter avg & NA & NA & NA & NA & 47.88 & 14.92 \\
\hline 9 & Boha- & 0 & Mean & 0.06829 & 0 & 0 & $\mathbf{0}$ & 0 & 0 \\
\hline & chevsky 2 & & $\mathrm{SD}$ & 0.07822 & 0 & 0 & 0 & 0 & 0 \\
\hline & & & Iter avg & NA & NA & NA & NA & 22.8 & 11.8 \\
\hline 10 & Boha- & 0 & Mean & $\mathbf{0}$ & $\mathbf{0}$ & O & $\mathbf{0}$ & $\mathbf{0}$ & $\mathbf{0}$ \\
\hline & chevsky 3 & & SD & 0 & 0 & 0 & 0 & 0 & 0 \\
\hline & & & Iter avg & NA & NA & NA & NA & 32.2 & 12.8 \\
\hline 11 & Schubert & -186.73 & Mean & -186.73 & -186.73 & -186.73 & -186.73 & -186.73 & -186.73 \\
\hline & & & SD & 0 & 0 & 0 & 0 & 0 & 0 \\
\hline & & & Iter avg & NA & NA & NA & NA & 144.32 & 11.52 \\
\hline 12 & Colville & 0 & Mean & 0.01494 & 0 & 1.11760 & 0.04091 & $\mathbf{0}$ & O \\
\hline & & & SD & 0.00736 & 0 & 0.46623 & 0.081898 & 0 & 0 \\
\hline & & & Iter avg & NA & NA & NA & NA & 1325.76 & 40.12 \\
\hline 13 & Micha- & -4.6877 & Mean & -4.64483 & -2.49087 & -4.6877 & -4.68348 & -4.6877 & -4.6877 \\
\hline & lewicz 5 & & SD & 0.09785 & 0.25695 & 0 & 0.01253 & 0 & 0 \\
\hline & & & Iter avg & NA & NA & NA & NA & 127.44 & 213.44 \\
\hline 14 & Zakharov & 0 & Mean & 0.01336 & $\mathbf{0}$ & O & $\mathbf{0}$ & $\mathbf{0}$ & $\mathbf{0}$ \\
\hline & & & $\mathrm{SD}$ & 0.00453 & 0 & 0 & 0 & 0 & 0 \\
\hline & & & Iter avg & NA & NA & NA & NA & 75.56 & 21.92 \\
\hline 15 & Micha- & -9.6602 & Mean & -9.49683 & -4.00718 & -9.6602 & -9.59115 & -9.6602 & -9.6602 \\
\hline & lewicz 10 & & SD & 0.14112 & 0.50263 & 0 & 0.06421 & 0 & 0 \\
\hline & & & Iter avg & NA & NA & NA & NA & 1394.2 & 1126.68 \\
\hline 16 & Step & 0 & $\begin{array}{l}\text { Mean } \\
\text { Stdv }\end{array}$ & $\begin{array}{l}1.17 \mathrm{E}+03 \\
76.56145\end{array}$ & $\begin{array}{l}\mathbf{0} \\
0\end{array}$ & $\begin{array}{l}5.12370 \\
0.39209\end{array}$ & $\begin{array}{l}\mathbf{0} \\
0\end{array}$ & $\begin{array}{l}\mathbf{0} \\
0\end{array}$ & $\begin{array}{l}\mathbf{0} \\
0\end{array}$ \\
\hline & & & Iter avg & NA & NA & NA & $\mathrm{NA}$ & 184.8 & 223.44 \\
\hline 17 & Sphere & 0 & Mean & $1.11 \mathrm{E}+03$ & 0 & O & $\mathbf{0}$ & $\mathbf{0}$ & $\mathbf{0}$ \\
\hline & & & SD & 74.21447 & 0 & 0 & 0 & 0 & 0 \\
\hline & & & Iter avg & NA & NA & NA & NA & 60.08 & 23.04 \\
\hline 18 & Sum & 0 & Mean & $1.48 \mathrm{E}+2$ & $\mathbf{0}$ & O & $\mathbf{0}$ & $\mathbf{0}$ & $\mathbf{0}$ \\
\hline & squares & & SD & 12.40929 & 0 & 0 & 0 & 0 & 0 \\
\hline & & & Iter avg & NA & NA & NA & NA & 56.8 & 22.28 \\
\hline 19 & Quartic & 0 & Mean & 0.18070 & 0.00116 & 1.72E-6 & 0.00136 & 7.41498E-05 & $1.43324 \mathrm{E}-05$ \\
\hline & & & SD & 0.0271 & 0.00028 & \begin{tabular}{|l|}
$1.85 \mathrm{E}-6$ \\
\end{tabular} & 0.00042 & $1.72271 \mathrm{E}-09$ & $6.54271 \mathrm{E}-11$ \\
\hline & & & Iter avg & NA & NA & NA & NA & 3000 & 3000 \\
\hline 20 & Schwefel & 0 & Mean & 11.0214 & $\mathbf{0}$ & $\mathbf{0}$ & $\mathbf{0}$ & $\mathbf{0}$ & $\mathbf{0}$ \\
\hline & 2.22 & & SD & 1.38686 & 0 & 0 & 0 & 0 & 0 \\
\hline
\end{tabular}




\begin{tabular}{|c|c|c|c|c|c|c|c|c|c|}
\hline & & & Iter avg & NA & NA & NA & NA & 101.08 & 38.72 \\
\hline \multirow[t]{3}{*}{21} & \multirow{3}{*}{$\begin{array}{c}\text { Schwefel } \\
1.2\end{array}$} & \multirow[t]{3}{*}{0} & Mean & $7.40 \mathrm{E}+3$ & $\mathbf{0}$ & $\mathbf{0}$ & $\mathbf{0}$ & $\mathbf{0}$ & $\mathbf{0}$ \\
\hline & & & SD & $1.14 \mathrm{E}+3$ & 0 & 0 & 0 & 0 & 0 \\
\hline & & & Iter avg & $\mathrm{NA}$ & $\mathrm{NA}$ & NA & NA & 63.96 & 24.52 \\
\hline \multirow[t]{3}{*}{22} & \multirow{3}{*}{$\begin{array}{c}\text { Rosen- } \\
\text { brok }\end{array}$} & \multirow[t]{3}{*}{0} & Mean & $1.96 \mathrm{E}+5$ & 15.088617 & 28.834 & 18.20394 & 0.270040821 & 0 \\
\hline & & & SD & $3.85+4$ & 25.170196 & 0.10597 & 5.03619 & 0.11285849 & 0 \\
\hline & & & Iter avg & NA & NA & NA & NA & 3000 & 1232.48 \\
\hline \multirow[t]{3}{*}{23} & \multirow{3}{*}{$\begin{array}{l}\text { Dixon } \\
\text { Price }\end{array}$} & \multirow[t]{3}{*}{0} & Mean & $1.22 \mathrm{E}+3$ & 0.66667 & 0.66667 & 0.66667 & 0.666666667 & 0.666666667 \\
\hline & & & SD & $2.66 \mathrm{E}+2$ & $1 \mathrm{E}-8$ & $1.16 \mathrm{E}-9$ & 1.E-9 & 0 & 0 \\
\hline & & & Iter avg & NA & NA & NA & NA & 3000 & 3000 \\
\hline \multirow[t]{3}{*}{24} & \multirow[t]{3}{*}{ Rastrigin } & \multirow[t]{3}{*}{0} & Mean & 52.92259 & 43.97714 & 0 & 11.71673 & 0 & 0 \\
\hline & & & SD & 4.56486 & 11.72868 & 0 & 2.53817 & 0 & 0 \\
\hline & & & Iter avg & NA & NA & NA & NA & 93.48 & 24.4 \\
\hline \multirow[t]{3}{*}{25} & \multirow{3}{*}{ Griewank } & \multirow[t]{3}{*}{0} & Mean & 10.63346 & 0.01739 & 0 & 0.00148 & 0 & $\mathbf{0}$ \\
\hline & & & SD & 1.16146 & 0.02081 & 0 & 0.00296 & 0 & 0 \\
\hline & & & Iter avg & NA & $\mathrm{NA}$ & NA & NA & 62.04 & 23.48 \\
\hline \multirow[t]{3}{*}{26} & \multirow[t]{3}{*}{ Ackley } & \multirow[t]{3}{*}{0} & Mean & 14.67178 & 0.16462 & 0 & $\mathbf{0}$ & $\mathbf{0}$ & $\mathbf{0}$ \\
\hline & & & SD & 0.17814 & 0.49387 & 0 & 0 & 0 & 0 \\
\hline & & & Iter avg & NA & NA & NA & NA & 99.08 & 38.6 \\
\hline
\end{tabular}

Note: NA=not available

benchmark functions compared to the GA, PSO, Bees Algorithm (BA), Differential Evolution (DE) and original SOS. NeSOS was built using the Matrix Laboratory software. This program is run using a laptop with a Core 2 Duo processor and 2.0 GB RAM. The parameter settings used for GA, PSO, BA, and DE follow [17], while for original SOS, and NeSOS are as follows: Ecosystem number $(n)=50$; Maximum of iteration $=3000 ;$ Error $=$ $1 \times 10^{-12}$. The algorithm is run 30 times for each benchmark function. The algorithm stops if the error is smaller than $1 \times 10^{-12}$ or the iteration equals the maximum iteration. The mean, standard deviation (SD) and iteration average (iter avg) are indicated in Table 3. Bolded numbers represent the best value for each function. Mean and SD values smaller than $1 \times 10^{-12}$ are considered the same as zero [17].

Table 3 shows that the proposed algorithm is more competitive compared to GA, PSO, BA, DE, and SOS. NeSOS can converge on 24 functions (except Quadratic and Dixon Price function), while SOS converge on 23 benchmark functions. GA has the worst performance, only converging on 10 of the 26 benchmark functions. PSO, DE, and BA are able to converge on 17, 18 and 19 benchmark functions respectively. GA, PSO, DE, and BA have difficulty converging on functions with larger dimensions such as Quadratic, Rosenbrok and Dixon Price functions. Although NeSOS on the Quadratic function does not reach the required error, it produces better values compared to GA, PSO, BA, DE, and SOS. For converging speed, NeSOS excels on 21 benchmarks, while SOS excels only on 3 benchmarks, namely: Step, Michalewicz 5, and Booth function. The use of RWIV and DPP accelerates the convergence rate of NeSOS $30 \%$ faster than SOS.

\subsection{Optimal location and size of DG}

NeSOS performance will be tested using location optimization and DG size on the IEEE 33 and IEEE 69 bus test system. The IEEE 33 bus radial distribution system consists of 32 lines and 33 buses. The total load connected to the IEEE 33 bus system is $3.72 \mathrm{MW}$ and 2.3 MVar. The IEEE 69 bus system consists of 68 lines and 69 buses. The total load connected to the system is $3.8 \mathrm{MW}$ and 2.69 MVar. The optimization results using NeSOS are compared with the improved analytic method (IA), PSO, hybrid analytic-PSO (hybrid), and SOS method [28].

\subsubsection{Objective functions and constrains}

In the distribution systems, active power loss depends on the resistance and line current. High line resistance results in a large power loss and voltage deviations. The objective function of DG optimization is active power loss reduction:

$$
F=\min \left(\sum_{\mathrm{i}=1}^{n} \sum_{\mathrm{j}=2}^{n} I_{\mathrm{ij}}^{2} R_{\mathrm{ij}}\right)
$$

Optimization is performed to determine the location and size of DG by minimizing the objective function in Eq. (14). The objective function must meet the following constraints:

a. The number of DG $\left(N_{D G}\right)$ must less or equal to the maximum number of DG ( $\left.N_{D G} \max \right)$. 


$$
N_{D G} \leq N_{D G} \max
$$

b. The active power of DG $\left(P_{D G}\right)$ is limited by its minimum $\left(P_{D G \max }\right)$ and maximum $\left(P_{D G \min }\right)$ limits.

$$
P_{D G \max } \leq P_{D G} \leq P_{D G \min }
$$

c. The total power generated by initial sources $\left(P_{g}\right)$ and DG units $\left(P_{D G}\right)$ must cover the total load demand $\left(P_{d}\right)$ and power loss $\left(P_{\text {loss }}\right)$.

$$
P_{g}+P_{D G}=P_{d}+P_{l o s s}
$$

d. The voltage on each bus $i\left(V_{i}\right)$ is limited by its minimum $\left(V_{i}^{\min }\right)$ and maximum $\left(V_{i}^{\max }\right)$ limits.

$$
V_{i}^{\min } \leq V_{i} \leq V_{i}^{\max }
$$

\subsubsection{Identification of DG locations}

The most difficult part in optimizing DG placement is determining the right locations of $\mathrm{DG}$ so that the objective function is optimal. For single DG, the possible combination of DG locations is the same as the number of buses in the system, so it is easy to determine. The number of DG location combinations will increase with increasing DG numbers, making it even more complicated.

Various approaches have been developed in determining DG locations. In this paper, the loss reduction sensitivity factor (LRSF) is used to identify the location of DG. LRSF value due to DG injection on the bus $i$ is formulated as follows [27]:

$$
L R S F_{i}=\frac{P_{\text {Loss }}^{i} P_{\text {Loss }}^{b}}{P_{D G_{\_} i}^{i n j}}
$$

$P_{\text {Loss }}^{i}=$ network loss due to DG injection on the bus $i$, $P^{b}{ }_{\text {loss }}=$ system loss prior to DG injection and $P^{i n j}{ }_{D G}=$ power injected by DG on the bus $i$.

The steps to determine the optimal DG location on a distribution system using LRSF are as follows:

1. Determine the number, size, and DG capacity.

2. DG injection into the distribution system using one DG. DG capacity is gradually increased and the LRSF value for each bus is recorded until the DG capacity is met.

3. Determine the optimal DG location based on the smallest LRSF value in step 2 .

4. Install DG in the optimal location according to step 3.

5. Continue steps 2-4 for the next DG unit, until all DG locations are known.
Table 4. LRSF and DG location for IEEE 33 bus System

\begin{tabular}{|c|c|c|c|}
\hline Scheme & DG Location & Size (MW) & LRSF \\
\hline 1 DG & 6 & 2.550 & -0.0386 \\
\hline \multirow{2}{*}{ 2 DG } & 13 & 0.850 & -0.0265 \\
\cline { 2 - 4 } & 30 & 0.850 & -0.0439 \\
\hline \multirow{3}{*}{ D DG } & 13 & 0.850 & -0.0265 \\
\cline { 2 - 4 } & 30 & 0.850 & -0.0439 \\
\cline { 2 - 4 } & 24 & 0.850 & -0.0499 \\
\hline
\end{tabular}

Table 5. LRSF and DG location for IEEE 69 bus System

\begin{tabular}{|c|c|c|c|}
\hline Scheme & DG Location & Size (MW) & LRSF \\
\hline 1 DG & 61 & 1.80 & -0.0215 \\
\hline 2 DG & 17 & 0.50 & -0.087 \\
\cline { 2 - 4 } & 61 & 1.80 & -0.0215 \\
\hline \multirow{3}{*}{3 DG } & 11 & 0.50 & -0.1106 \\
\cline { 2 - 4 } & 17 & 0.50 & -0.0870 \\
\cline { 2 - 4 } & 61 & 1.80 & -0.0215 \\
\hline
\end{tabular}

Following the procedures above, the lowest LRSF and optimal locations of DG for IEEE 33 and IEEE 69 bus systems are presented in Table 4 and Table 5 .

\subsubsection{Optimal sizing of DG}

After determining the optimal location of DG using LRSF, optimal sizing of DG is performed using back-forward load flow and NeSOS. The type of DG used is DG which is only capable of injecting real power. The optimization scheme consists of 3 schemes, namely $1 \mathrm{DG}, 2 \mathrm{DG}$, and $3 \mathrm{DG}$. The optimization results are compared with hybrid PSO, PSO, IA, and SOS. The parameter settings for NeSOS and SOS are: Ecosystem number $(n)=50$; maximum of iteration $=100$. The algorithm is run 10 times for each scheme. Parameter settings for PSO, hybrid PSO and IA follow parameters in [28]. Tables 6 and 7 show the results of DG optimization for the IEEE 33 and the IEEE 69 bus system.

IA is an analytical method based on mathematical expressions that integrates the DG model into the load flow. It is well known that analytic methods have limitations in mathematical modelling for non differential or complex problems, which affects inaccurate results. The hybrid method combines analytic and PSO methods. PSO is used to determine the location while DG size is determined using analytic methods. PSO has precisely determined the optimal DG location, but the analytic method failed to determine the DG size accurately. PSO itself has problems with many parameters that need to be adjusted to ensure a balance between exploration and exploitation. The improper parameters settings affect the accuracy of the PSO results. Unlike PSO, NeSOS does not have special control parameters, so this algorithm is robust and 
Table 6. Optimal location and size of DG on IEEE 33 bus System

\begin{tabular}{|c|c|c|c|c|c|c|c|c|}
\hline Scheme & Method & $\begin{array}{c}\text { Bus } \\
\text { Location }\end{array}$ & $\begin{array}{c}\text { Sise } \\
(\mathbf{M W})\end{array}$ & & $\begin{array}{l}\text { Capacity } \\
\text { (MW) }\end{array}$ & $\begin{array}{c}\text { Power } \\
\text { Loss }(k W)\end{array}$ & $\begin{array}{c}\text { Loss } \\
\text { Reduction }(\%)\end{array}$ & Iteration \\
\hline No DG & - & - & - & & - & 211 & - & - \\
\hline \multirow[t]{5}{*}{$1 \mathrm{DG}$} & Hybrid [28] & 6 & 2.49 & & 2.49 & 111.7 & 50.356 & $\mathrm{NA}$ \\
\hline & PSO [28] & 6 & 2.59 & & 2.59 & 111.03 & 50.653 & NA \\
\hline & IA[28] & 6 & 2.60 & & 2.6 & 111.1 & 50.622 & NA \\
\hline & SOS & 6 & 2.59 & & 2.59 & 111.02 & 50.658 & 4.3 \\
\hline & NeSOS & 6 & 2.59 & & 2.59 & 111.02 & 50.658 & 2.5 \\
\hline \multirow[t]{5}{*}{$2 \mathrm{DG}$} & Hybrid [28] & $13 \quad 30$ & 0.83 & & 1.94 & 87.28 & 61.209 & NA \\
\hline & PSO [28] & $13 \quad 30$ & 0.85 & & 2.01 & 87.17 & 61.258 & NA \\
\hline & IA[28] & $\begin{array}{ll}6 & 14 \\
\end{array}$ & 1.80 & & 2.52 & 91.63 & 59.276 & NA \\
\hline & SOS & $13 \quad 30$ & $0.852 \quad 1.158$ & & 2.01 & 87.16 & 61.262 & 21.9 \\
\hline & NeSOS & $13 \quad 30$ & $0.852 \quad 1.158$ & & 2.01 & 87.16 & 61.262 & 9.2 \\
\hline \multirow[t]{5}{*}{$3 \mathrm{DG}$} & Hybrid [28] & $\begin{array}{lll}13 & 24 & 30 \\
\end{array}$ & $\begin{array}{ll}0.79 & 1.07 \\
\end{array}$ & 1.01 & 2.87 & 72.89 & 67.604 & NA \\
\hline & PSO [28] & $13 \quad 24 \quad 30$ & 0.77 & 1.07 & 2.93 & 72.79 & 67.649 & NA \\
\hline & IA[28] & $\begin{array}{lll}6 & 12 & 31 \\
\end{array}$ & 0.90 & 0.72 & 2.52 & 81.05 & 63.978 & NA \\
\hline & SOS & $\begin{array}{lll}13 & 24 & 30 \\
\end{array}$ & $\begin{array}{ll}0.802 & 1.091 \\
\end{array}$ & 1.054 & 2.947 & 72.78 & 67.653 & 32.5 \\
\hline & NeSOS & $\begin{array}{lll}13 & 24 & 30 \\
\end{array}$ & $\begin{array}{ll}0.802 & 1.091 \\
\end{array}$ & 1.054 & 2.947 & 72.78 & 67.653 & 13.7 \\
\hline
\end{tabular}

Note: $\mathrm{NA}=$ not available

Table 7. Optimal location and size of DG on IEEE 69 bus System

\begin{tabular}{|c|c|c|c|c|c|c|c|c|}
\hline Scheme & Method & $\begin{array}{c}\text { Bus } \\
\text { Location }\end{array}$ & & $\begin{array}{l}\text { Sise } \\
(\mathrm{MW})\end{array}$ & $\begin{array}{l}\text { Capacity } \\
\text { (MW) }\end{array}$ & $\begin{array}{c}\text { Power } \\
\text { Loss }(k W)\end{array}$ & $\begin{array}{c}\text { Loss } \\
\text { Reduction (\%) }\end{array}$ & Iteration \\
\hline No DG & - & - & & - & - & 225 & - & - \\
\hline \multirow[t]{4}{*}{$1 \mathrm{DG}$} & Hybrid [28] & 61 & 1.81 & & 1.81 & 83.37 & 62.947 & NA \\
\hline & PSO [28] & 61 & 1.87 & & 1.87 & 83.22 & 63.013 & NA \\
\hline & SOS & 61 & 1.872 & & 1.872 & 83.22 & 63.013 & 1.8 \\
\hline & NeSOS & 61 & 1.872 & & 1.872 & 83.22 & 63.013 & 1.6 \\
\hline \multirow[t]{4}{*}{$2 \mathrm{DG}$} & Hybrid [28] & $17 \quad 61$ & 0.52 & 1.72 & 2.24 & 71.80 & 68.089 & NA \\
\hline & PSO [28] & $17 \quad 61$ & 1.78 & 0.53 & 2.31 & 71.68 & 68.142 & NA \\
\hline & SOS & $17 \quad 61$ & 0.531 & 1.781 & 2.31 & 71.67 & 68.145 & 14.3 \\
\hline & $\mathrm{NesOS}$ & $17 \quad 61$ & 0.531 & 1.781 & 2.31 & 71.67 & 68.145 & 5.2 \\
\hline \multirow[t]{4}{*}{$3 \mathrm{DG}$} & Hybrid [28] & $\begin{array}{lll}11 & 17 & 61 \\
\end{array}$ & 0.510 & $\begin{array}{ll}0.38 & 1.67 \\
\end{array}$ & 2.56 & 69.54 & 69.09 & NA \\
\hline & PSO [28] & $\begin{array}{lll}11 & 17 & 61 \\
\end{array}$ & 0.460 & $0.44 \quad 1.70$ & 2.60 & 69.54 & 69.09 & NA \\
\hline & SOS & $\begin{array}{lll}11 & 17 & 61 \\
\end{array}$ & 0.527 & $0.381 \quad 1.719$ & 2.626 & 69.43 & 69.14 & 24.6 \\
\hline & NeSOS & $\begin{array}{lll}11 & 17 & 61 \\
\end{array}$ & 0.527 & $0.381 \quad 1.719$ & 2.626 & 69.43 & 69.14 & 10.5 \\
\hline
\end{tabular}

Note: NA=not available

has a good convergence speed. The integration of RWIV and DPP increases the computational time efficiency and accuracy of the NeSOS. As seen in Table 6, NeSOS has a better performance compared to Hybrid, PSO, IA, and SOS. For accuracy, NeSOS and SOS excel in all schemes of optimization.

NeSOS and SOS provide the smallest loss compared to Hybrid, PSO and IA methods. NeSOS and SOS resulted in loss $111.02 \mathrm{~kW}, 87.16 \mathrm{~kW}$ and $72.78 \mathrm{~kW}$ for schemes 1, 2 and 3 respectively. DG injection into the power system, in addition to minimizing power loss, also improves voltage deviation. The minimum bus voltage before DG injection is 0.903 pu on bus 18. DG injection increases the minimum bus voltage to $0.94 \mathrm{pu}, 0.96 \mathrm{pu}$ and $0.97 \mathrm{pu}$ for the first, the second, and the third scheme respectively. The bus voltages before and after DG injection are shown in Fig. 4. In terms of convergence speed,
NeSOS is $52.6 \%$ faster than SOS. Curve convergence of NeSOS and SOS are shown in Fig. 5.

Optimization DG using IEEE 69 bus test system, NeSOS and SOS produce the smallest loss in the second and the third scheme, while in the first scheme NeSOS produce the same value as SOS and PSO. Power loss before DG placement is $225 \mathrm{~kW}$. DG injection resulted in a reduction in loss of $83.22 \mathrm{~kW}, 71.67 \mathrm{~kW}$ and $69.43 \mathrm{~kW}$ for the first, the second and the third scheme respectively.

The reduction of power loss is also followed by an increase in bus voltage. The minimum bus voltage before placement of DG is $0.908 \mathrm{pu}$ on bus 65. DG injection on bus 61 of $1.872 \mathrm{MW}$ significantly increases the system bus voltage. The minimum bus voltage is $0.968 \mathrm{pu}$. DG injection on 


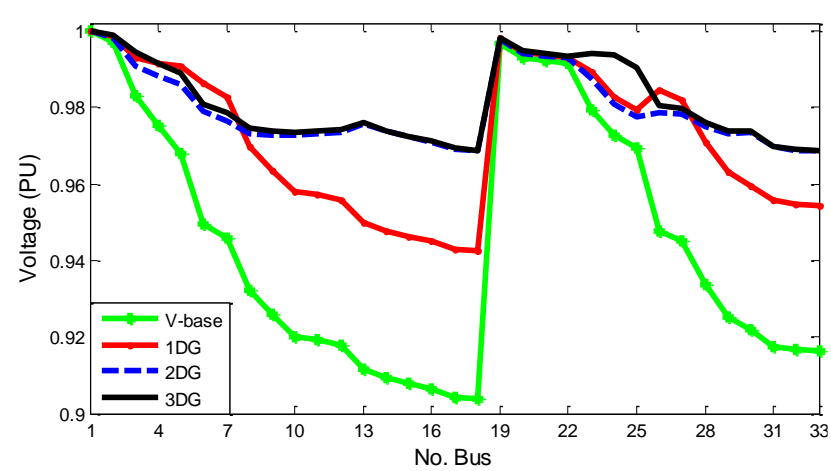

Figure. 4 Bus voltages before and after DG placement on the IEEE 33 bus system

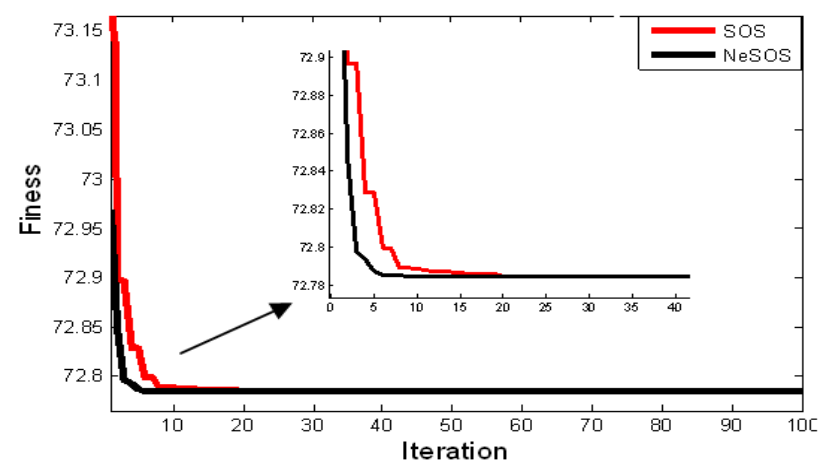

Figure. 5 Curve convergence of NeSOS and SOS

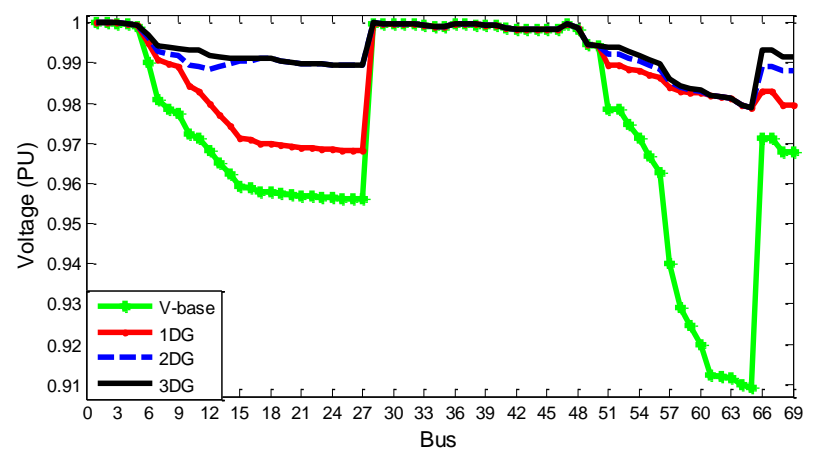

Figure. 6 Bus voltages before and after DG placement on the IEEE 69 bus system

buses 17 and 61 with a total of $2.31 \mathrm{MW}$ produces a minimum bus voltage of 0.978 pu. Scheme 3 does not provide a significant increase in bus voltage. The minimum bus voltage is $0.979 \mathrm{pu}$. The bus voltage before and after DG placement on the IEEE 69 bus system is shown in Fig. 6. In terms of convergence speed, NeSOS is superior to SOS. NeSOS is $44.04 \%$ faster than SOS on average.

\section{Conclusions}

This research proposes improvements to the original SOS by using RWIV and DPP called NeSOS. RWIV and DPP are used to increase the variability of organisms in the ecosystem so that an optimal global is achieved. The validation results using 26 benchmark functions show that NeSOS is superior both in terms of accuracy and convergence speed. NeSOS can converge on 24 of 26 benchmark functions with better accuracy than other methods. For converging speed, NeSOS excels on 21 benchmarks, while SOS excels only on 3 benchmarks function. NeSOS is $30 \%$ faster than SOS. NeSOS validation on DG location and size optimization shows that NeSOS has succeeded in providing the smallest loss. NeSOS provides an average power loss of $1.53 \%$ lower than other methods. Based on the results of the validation, it can be concluded that NeSOS has a higher capability in finding optimal solutions.

For further studies, it will be interesting to hybridize the SOS algorithm with other algorithms to improve its performance. In addition, comparisons with other SOS variants that exist in various kinds of literature need to be studied more deeply to check the effectiveness of the proposed algorithm. Implementation of the NeSOS algorithm in solving more complex engineering problems will be further work.

\section{Conflicts of Interest}

This article has not been published and is not under consideration for publication elsewhere. All authors have read and approved the manuscript and take full responsibility for its content. The authors have no conflict of interest in regard to this research or its funding.

\section{Author Contributions}

Conceptualization, Umar Umar; methodology, Umar Umar; software, G. Setyawan and Dimas Fajar U.P; validation, Faanzir Faanzir, Firdaus Firdaus, and Dimas Fajar UP; formal analysis, Umar Umar, and G. Setyawan; investigation, G. Setyawan; resources, Faanzir Faanzir, and Firdaus Firdaus; data curation, Faanzir Faanzir, and Firdaus Firdaus; writingoriginal draft preparation, Umar Umar; writingreview and editing, Umar Umar, Adi Soperijanto, and Ontoseno Penangsang; visualization, Umar Umar and Dimas Fajar U.P; supervision, Adi Soperijanto, and Ontoseno Penangsang; funding acquisition, Faanzir Faanzir, and Firdaus Firdaus.

\section{Acknowledgments}

The author would like to thank the government of the Republic of Indonesia, for financial support through the BPP-DN Scholarship to pursue a Doctoral Program at the Department of Electrical Engineering, Institut Teknologi Sepuluh Nopember, Indonesia. The author also thanks anonymous reviewers for their valuable suggestions. 


\section{References}

[1] A. Colmenar-Santos, C. Reino-Rio, D. BorgeDiez, and E. Collado-Fernández, "Distributed Generation: A Review of Factors That Can Contribute Most to Achieve A Scenario of DG Units Embedded in The New Distribution Networks", Renewable and Sustainable Energy Reviews, Vol. 59, pp. 1130-1148, 2016.

[2] M. M. Aman, G. B. Jasmon, H. Mokhlish, and A. H. A. Bakar, "Optimal Placement and Sizing of A DG Based on A New Stability Index and Line Losses", International Journal Electrical Power and Energy System. Vol. 43, No. 1, pp. 1296-1304, 2012.

[3] S. Essalah, A. Khedder, and A. Boualleque, "Integration of DG in Electrical Grid: Optimal Placement and Sizing under Different Load Conditions", Computers and Electrical Engineering, Vol. 79, pp. 1-14, 2019.

[4] B. Das, V. Mukherjee, and D. Das, "Optimum DG Placement for Known Power Injection from Utility/Substation by A Novel Zero Bus Load Flow Approach", Journal of Energy, Vol. 175, pp. 228-249, 2019.

[5] M. A. Abdelkader, M. A. Elshahed, and Z. H. Osman, "An Analytical Formula for Multiple DGs Allocations to Reduce Distribution System Losses", Alexandria Engineering Journal, Vol. 58, pp. 1265-1280, 2019.

[6] T. S. Tawfeek, A. H. Ahmed, and S. Hasan, "Analytical and Particle Swarm Optimization Algorithms for Optimal Allocation of Four Different Distributed Generation Types in Radial Distribution Networks", Energy Procedia, Vol. 153, pp. 86-94, 2018.

[7] K. H. Truong, P. Nallagownden, Z. Baharudin, and D.N.Vo, "A Quasi-Oppositional-Chaotic Symbiotic Organisms Search Algorithm for Global Optimization Problems", Applied Soft Computing, Vol. 77, pp. 567-583, 2019.

[8] Umar, Firdaus, A. Soeprijanto, and O. Penangsang, "Optimal Expenditure and Benefit Cost Based Location, Size and Type of DGs in Microgrids Systems Using Adaptive Real Coding Genetic Algorithm", Telkomnika, Vol. 16, No. 1, pp. 10-17, 2018.

[9] W. Da Rosa, C. Gerez, and E. Belati, "Optimal DG Allocating Using Particle Swarm Optimization and Linearized AC Load Flow", IEEE Latin America Transactions, Vol. 16, No. 10, pp. 2665-2670, 2018.

[10] D. Manna, S. K. Goswami, and P. K. Chattopadhyay, "Optimisation of Droop Coefficients of Multiple DG in A Micro-Grid",
IET Generation, Transmission \& Distribution, Vol. 12, No. 18, pp. 4108-4116, 2018.

[11] D. H. Wolpert and W. G. Macready, "No Free Lunch Theorems for Optimization", IEEE Transaction Evolution Computing, Vol. 1, pp. 67-82, 1997

[12] X. S. Yang, "Flower Pollination Algorithm for Global Optimization", Computer Science, Vol. 7445, pp. 240-249, 2012.

[13] X. Pan, L. Xue, and R. Li, "A New and Efficient Firefly Algorithm for Numerical Optimization Problems", Neural Computing and Application, Vol. 31, pp. 1445-1453, 2019.

[14] S. Mirjalili, S. M. Mirjalili, and A. Lewis, "Grey Wolf Optimizer", Advances in Engineering Software, Vol. 69, pp. 46-61, 2014.

[15] S. Mirjalili, "The Ant Lion Optimizer", Advances in Engineering Software, Vol. 83, pp. 80-98, 2015.

[16] A. Askarzadeh, "A Novel Metaheuristic Method for Solving Constrained Engineering Optimization Problems: Crow Search Algorithm", Computers and Structures, Vol. 169, pp. 1-12, 2016.

[17] M. Y. Cheng and D. Prayogo, "Organisms Search: A New Metaheuristic Optimization Algorithm", Computers and Structures, Vol. 139, pp. 98-112, 2014.

[18] G. Setyawan, Umar, A. Soeprijanto, and O. Penangsang, "Symbiotic Organism Search for Sizing and Optimal Location of DG Using Novel Sensitivity Factor", In: Proc. of IOP Conference Series: Material Science and Engineering, Vol. 588, pp. 1-7, 2019.

[19] B. Das, V. Mukherjee, and D. Das, "DG Placement in Radial Distribution Network by Symbiotic Organisms Search Algorithm for Real Power Loss Minimization", Applied Soft Computing, Vol. 49, pp. 920-936, 2016.

[20] S. A. Sharhan and M. G. H. Othman, "An Enhanced Symbiosis Organisms Search Algorithm: An Empirical Study", Journal of Neural Computing and Applications, Vol. 29, No. 11, pp. 1025-1043, 2016.

[21] L. R. Rodrigues, J. P. P. Gomes, A. R. R. Neto, and A. H. Souza, "A Modified Symbiotic Organisms Search Algorithm Applied to Flow Shop Scheduling Problems", In: Proc. of IEEE Congress on Evolutionary Computation (CEC), Rio de Janeiro, pp.1-7, 2018.

[22] A. Panda and S. Pani, "An Orthogonal Parallel Symbiotic Organism Search Algorithm Embodied with Augmented Lagrange Multiplier for Solving Constrained 
Optimization Problems", Soft Computing, Vol. 22, pp. 2429-2447, 2018.

[23] S. Kumar, G. G. Tejani, and S. Mirjalili, "Modified Symbiotic Organisms Search for Structural Optimization", Engineering with Computers, Vol. 35, pp. 1269-1296, 2019.

[24] E. Celik, "A Powerful Variant of Symbiotic Organisms Search Algorithm for Global Optimization", Engineering Applications of Artificial Intelligence, Vol. 87, pp. 1-14, 2020.

[25] D. T. T. Do, and J. Lee, "A Modified Symbiotic Organisms Search (mSOS) Algorithm for Optimization of Pin-Jointed Structures", Applied Soft Computing, Vol. 61, pp. 683-699, 2017.
[26] S. C. Sataphaty and A. Naik, "Improved Teaching Learning Based Optimization for Global Function Optimization", Decision Letter, Vol. 2, No. 1, pp. 23-34, 2013

[27] A. K. Singh and S. K. Parida, "Novel Sensitivity Factors for DG Placement Based on Loss Reduction and Voltage Improvement", Electrical Power and Energy Systems, pp. 1-4, 2015.

[28] S. Kansal, V. Kumar, and B. Tyagi, "Hybrid Approach for Optimal Placement of Multiple DGs of Multiple Types in Distribution Networks", Electrical Power and Energy Systems, Vol. 75, pp. 226-235, 2016. 